significativamente mayor (mediana 5; IQR 4,7) que los sujetos con enfermedad crónica (mediana 3; IQR 2,4); ( $<<0,0001)$.

Estos hallazgos sugieren que las evaluaciones de fragilidad capturan un factor diferente de mala salud en niños evaluados para trasplante que no es valorado por el laboratorio de rutina, o por las evaluaciones nutricionales en niños con enfermedad hepática.

Los elementos que contribuyeron a las puntuaciones de fragilidad más altas en niños con enfermedad hepática fueron el agotamiento (fatiga), la disminución de la actividad física y también la alta prevalencia del deterioro de la fuerza periférica. Este último factor, es muy importante en niños con enfermedad hepática, dado que proporciona una justificación para estudios futuros de la superficie del área del psoas cuya disminución se denomina sarcopenia, considerada hoy como un correlato biológico de la fragilidad y el deterioro de la fuerza. ${ }^{3}$

El inconveniente de este trabajo es que fue realizado en una cohorte pequeña y que las herramientas utilizadas son para niños a partir de los 5 años y gran parte de aquellos que requieren un trasplante están por debajo de esta edad. Probablemente en un futuro cercano, diferentes cuestionarios como el PedQls puedan ser utilizados complementariamente para valorar diversos estados, incluyendo la fatiga, en los más pequeños.

Actualmente, esta nueva apertura en la evaluación del paciente, abre un espacio amplio para la interpretación de otras enfermedades crónicas y asimismo, podría ayudar a comprender un estado real del deterioro y planificar estrategias para disminuir los riesgos.

Quizás, pocos han definido con tanto acierto el significado de la palabra fragilidad como Jorge Luis Borges quien en su "Poemas de los dones" escribió "Nadie rebaje la lágrima o reproche esta declaración de la maestría de Dios que con magnífica ironía me dio a la vez los libros y la noche".

\section{Dr. Daniel Eduardo D'Agostino Servicio de Gastroenterología-Hepatología Trasplante Hepático-Intestinal Departamento de Pediatría Hospital Italiano de Buenos Aires}

Correspondencia: daniel.dagostino@hiba.org.ar

http:/ / dx.doi.org/10.5546/ aap.2019.356

Texto completo en inglés:

http:/ / dx.doi.org/10.5546/ aap.2019.eng.356

Cómo citar: D’Agostino DE. La fragilidad, más allá de una palabra. Arch Argent Pediatr 2019;117(6):356-357.

\section{REFERENCIAS}

1. Fried LP, Tangen CM, Watson J, Newman AB, et al. Frailty in older adults: Evidence of a Phenotype. J Gerontol A Biol Sci Med Sci. 2001; 56(3):M146-56.

2. Lurz E, Quammie C, Englesbe M, Alonso E, et al. Frailty in Children with liver Disease: A Prospective Multicenter Study. J Pediatr. 2018; 194:109-15.e4.

3. Lurz E, Patel H, Frimpong RG, Ricciuto A, et al. Sarcopenia in Children With End-Stage Liver Disease. J Pediatr Gastroenterol Nutr. 2018; 66(2):222-6.

\title{
Epistemología de la introspección: la clave interior de la investigación científica
}

The epistemology of introspection: the inner key to scientific research

\section{La ilusoria separación sujeto-objeto}

Desde un análisis superficial, pareciera que un/a científico/a y aquello que investiga son entidades independientes entre sí, sin embargo desde un análisis profundo resulta claro que no es así, pues investigador y objeto investigado son parte de un todo donde coparticipan del eterno juego de intercambio de los elementos. Así por ejemplo, a un/a investigador/a y al animal de laboratorio que él/ella estudia los une, entre otras cosas, el intercambio del aire que respiran; es decir que el/la investigador/a es un fragmento autoconsciente del mundo capaz de observar y analizar a otro fragmento del mismo. ${ }^{1}$ Habitualmente el/la investigador/a cree que descubre leyes naturales merced a la observación y análisis de un mundo "externo" a él/ella. Sin embargo, en realidad el/la investigador/a redescubre leyes que desde siempre han estado en él/ella, ya que al ser un fragmento del mundo, se 
ve atravesado/a por dichas leyes. ${ }^{2,3}$ El proceso de investigación constituye entonces una suerte de instrumento que contribuye al alumbramiento de leyes naturales que desde siempre residen en el "interior" del investigador/a, facilitando su pasaje de la oscuridad de su inconsciente a la luz de su consciente. El/la investigador/a, como fractal del universo, contiene todos los secretos del mismo, sólo que escritos en un lenguaje natural (genéticosimbólico) de formas, sonidos y movimientos, común a todo el mundo natural (inorgánico y orgánico), pero ilegible para la consciencia humana, cuyo leguaje es el de las palabras (signos). Es menester llevar a cabo una traducción de uno a otro lenguaje a fin de que dicho alumbramiento acontezca. La correspondencia entre estos lenguajes se basa en que están emparentados, pues la palabra (lenguaje del consciente) procede evolutivamente del símbolo (lenguaje del inconsciente), y éste procede de las formas, colores y movimientos de la naturaleza (lenguaje natural). Así por ejemplo, la ley de la gravitación universal fue descripta (concientizada) por Isaac Newton en 1687, sin embargo desde siempre animales y humanos "supieron" del riesgo de caer de la cima de las montañas, al contar con un registro de la ley de gravitación universal a nivel de su inconsciente colectivo. $^{3-5}$

\section{El lenguaje simbólico como reflejo del mundo natural}

El lenguaje del mundo natural no se basa en palabras (signos) sino en formas, colores y movimientos (pre-símbolos), susceptibles de ser captados por los sentidos e interpretados en forma instintiva-intuitiva al traducirse a un lenguaje de imágenes mentales (símbolos) en un plano somático-encefálico subcortical (inconsciente), lugar de asiento de todo el "acervo ingenieril" natural. En el caso del ser humano, fragmento del mundo natural con capacidad racional, este lenguaje natural se encuentra archivado simbólicamente en su inconsciente individual y colectivo, expresándose en sus producciones oníricas y artísticas. En el lenguaje artístico, variante humana del lenguaje natural, radica la capacidad de explorar lo inefable y de poder concentrar un conjunto de sensaciones interiores en una percepción integradora (intuición). Desde el arte, el hombre posee una perspectiva más parecida a la perspectiva original pre-verbal, propia de la mente prehistórica e infantil, vale decir de aquel tiempo en que aún no estaba consolidada la ilusoria separación sujeto-objeto, y reinaba una percepción por fuera de las categorías lingüísticas. ${ }^{6}$

\section{El investigador como principal instrumento de investigación}

De lo antes expuesto, queda claro que el principal instrumento de investigación es el investigador mismo, quien al momento de tener que explicar un fenómeno, elabora una hipótesis nacida del ejercicio de su fantasía-intuición, basada en ingredientes de su inconsciente (personal y colectivo). Dichos ingredientes proceden de su archivo natural inconsciente, $y$ logran pasar de su localización somática-mental subcortical al plano consciente (recuerdo de sí) merced al proceso investigativo. Sólo la posterior confirmación de la validez de dicha hipótesis científica mediante su contrastación contra los hechos del mundo logrará discernir, hasta cierto grado, si dicha hipótesis fue producto de la fantasía (irrealidad creada por la mente) o de la intuición (realidad percibida por medio de un razonamiento inconsciente). Sin embargo, dado que el método científico se basa en la inducción (reunión de casos), la ciencia nunca determina la veracidad de una hipótesis, ya que resulta imposible reunir la totalidad de los casos necesarios para su confirmación, sino que solo puede reunir un número suficiente de casos como para poder determinar su aparente veracidad (verosimilitud), mientras no sea demostrada su falsedad. Resulta entonces que la distinción entre aquello creado por la mente (fantasía) y aquello redescubierto por ella (intuición) es siempre provisorio, de modo que fantasía e intuición pueden englobarse en una sola actividad mental denominada imaginación, la cual siempre se nutre del inconsciente y resulta indispensable para el desarrollo de la investigación científica. Este instrumento de investigación constituido por la conciencia del investigador y su capacidad de imaginación activa, requiere de la realización de una conexión por un lado con el objeto de estudio, y por otro con su saber inconsciente, que es parte del archivo natural del mundo, la cual se basa al menos de dos condiciones favorecedoras:-9

- El ejercicio de la empatía.

- La claridad de la conciencia.

La empatía se define usualmente como la capacidad de comprender los sentimientos de otra persona, sin embargo esta capacidad puede llegar a experimentarse incluso con los animales y las cosas (empatía universal). La experiencia 
de la empatía requiere por un lado, la apertura para reconocer al otro (sujeto u objeto), y la paciencia para experimentar transitoriamente una situación o estado ajeno en "carne propia", en pos de comprenderlo, y luego "alejarse" para analizar con la mayor objetividad posible lo experimentado. En el acto empático existe una expansión de los horizontes vivenciales, una desaparición de los límites arbitrarios del ego, del espacio y del tiempo. ${ }^{10}$

La empatía al decodificar a nivel límbico (inconsciente) un lenguaje natural (inefable), facilita su pasaje a un lenguaje de palabras (consciente). La empatía sería entonces el proceso mental que logra la traducción del lenguaje natural (imágenes del mundo) al lenguaje de la conciencia (palabras), pasando entre uno y otro por el leguaje simbólico (imágenes mentales). Esto significa que el pensamiento intuitivo conlleva una doble traducción desde el lenguaje de las cosas (natural), al de las imágenes mentales (simbólico) y finalmente al de las palabras (sígnos). Precisamente en esto se fundamenta la hipótesis que sostiene que la exposición del investigador a ambientes con alta carga simbólica, tales como escenarios naturales o con marcada presencia de obras artísticas, podrían facilitar el pasaje de contenidos del campo del inconsciente al campo de la conciencia, a través de la estimulación empática, que de esta forma brindaría materia prima para su trabajo a la imaginación (fantasía-intuición). En cuanto al concepto de claridad de consciencia, éste implica la necesidad por parte del investigador de lograr mediante la observación de sí (autoobservación), en la medida de lo posible, una conciencia libre de actos psíquicos mecánicos (ruido mental), tales como la identificación con emociones negativas (miedo, envidia, codicia, prejuicios) o un excesivo apego al ego (vanidad, egoísmo), ya que todos ellos conducen a la estrechez mental, la pérdida de la objetividad crítica, de la libertad de pensamiento y de la capacidad empática e imaginativa de la mente. Dado que el nivel evolutivo del ser condiciona el nivel de compresión del individuo, el desarrollo interior del científico propiciaría entonces en él un adecuado flujo empático inconscienteconsciente, y por ende una fructífera capacidad de introspección y generación de ideas.

\section{CONCLUSIÓN}

La epistemología de la introspección sostiene que dado que el investigador es el principal instrumento de investigación, y que las leyes del mundo natural residen en su inconsciente, el desarrollo en él de una capacidad empática y de una conciencia clara producto de su evolución personal, redundaría en una mejor conectividad inconsciente-consciente, y por ende en una mejor producción científica.

Dr. Carlos G. Musso. Instituto Universitario del Hospital Italiano de Buenos Aires, Argentina

http:/ / dx.doi.org/10.5546/aap.2019.357

Texto completo en inglés:

http:/ / dx.doi.org/10.5546/aap.2019.eng.357

Cómo citar: Musso CG. Epistemología de la introspección: la clave interior de la investigación científica. Arch Argent Pediatr 2019;117(6):357-359.

\section{REFERENCIAS}

1. Suzuki D, Fromm E. Budismo zen y psicoanálisis. Mexico, D.F.: Fondo de Cultura Económica; 1964.

2. Fromm E. El lenguaje olvidado. Barcelona: Paidos; 2012.

3. CirlotJE.Dictionary of symbols. 2nd ed.London:Routledge; 1971.

4. Jung CG. Arquetipos e inconsciente colectivo. Barcelona: Paidos; 1970.

5. Jung CG. Símbolos de transformación. Barcelona: Paidos; 1963.

6. Musso CG. La intersección de las paralelas: arte y ciencia en un único proceso cognitivo. Hacia una nueva forma de investigar. Rev Hosp Ital B Aires. 2012;32(1):1-2.

7. Musso CG, Dricas D, González-Torres H. Apicación del arte en la investigación científica: fundamentos de un método original para su utilización. Arch Argent Pediatr. 2018;116(5):353-8.

8. Nicoll M. Comentarios piscológicos sobre las enseñanzas de Gurdieff y Oupensky. London: Kier; 1944.

9. Farber M. Husserl. Buenos Aires: Losange; 1956.

10. Musso CG, Enz P. Arte y naturaleza humana XII. Rev Hosp Ital B Aires. 2013;33(2):71-2. 